\title{
SIREUBOH: KLASIFIKASI DATA LOKASI BARANG MENGGUNAKAN REGION $O F$ INTEREST (ROI) DAN ALGORITMA RANSAC
}

\author{
Syafrial Fachri Pane ${ }^{1}$, Rolly Maulana Awangga ${ }^{2}$, Maulyanda ${ }^{3}$ \\ 1,2,3 Program Studi D4 Teknik Informatika, Politeknik Pos Indonesia \\ ${ }^{1}$ syafrial.fachri@poltekpos.ac.id \\ 2awangga@poltekpos.ac.id \\ ${ }^{3}$ maulyanda@if.poltekpos.ac.id
}

\begin{abstract}
Abstrak - Perusahaan yang bergerak pada bidang logistik membutuhkan inovasi untuk meningkatkan daya saing dalam memberikan layanan terbaik mereka kepada konsumen, salah satunya pada Warehouse Management System (WMS) karena sistem tersebut masih kesulitan dalam mencocokkan data lokasi dengan sistem Logistics Execution System (LES) yang dipakai konsumen. sehingga pada bagian operation system management masih kesulitan dalam proses penempatan barang. Penelitian ini menggunakan algoritma RANSAC untuk mengukur keakuratan data lokasi barang pada proses penempatan barang yang sesuai, Region Of Interest (ROI) untuk memperkecil ruang lingkup data lokasi barang. Hasil analisis yang telah dilakukan dengan melakukan pencocokan data WMS dan LES didapatkan nilai persentase sebesar $87 \%$ untuk tingkat keakuratan data lokasi barang dengan mengolah 100 sample data lokasi barang yang dimiliki perusahaan. Hasil penelitian ini menunjukkan sangat bermanfaat karena dapat melakukan pencocokan data berdasarkan lokasi barang.
\end{abstract}

Kata kunci : WMS, LES, Algoritma RANSAC, ROI.

\begin{abstract}
Companies that are engaged in logistics need innovation to improve competitiveness in providing their best services to consumers, one of which is the Warehouse Management System (WMS) because the system is still having difficulty matching location data with the Logistics Execution System (LES) system used by consumers. so that in the operation system management section there are still difficulties in the process of placing goods. This study uses the RANSAC algorithm to measure the accuracy of item location data in the process of placing the appropriate goods, Region of Interest (ROI) to reduce the scope of the location data of goods. The results of the analysis that have been done by matching WMS and LES data obtained a percentage value of $87 \%$ for the level of accuracy of the location data of goods by processing 100 samples of location data of goods owned by the company. The results of this study indicate that it is very useful because it can do data matching based on the location of the item.
\end{abstract}

Keywords : WMS, LES, RANSAC Algorithm, ROI.

\section{PENDAHULUAN}

Pemerintah Republik Indonesia saat ini sedang fokus membangun infrastruktur logistik agar memperlancar distribusi logistik ke seluruh daerah-daerah di Indonesia. Definisi dari Logistik adalah orientasi perencanaan dan kerangka kerja yang berusaha menciptakan satu rencana untuk aliran produk dan informasi melalui bisnis (Christopher;2016). Logistik di Indonesia saat ini menyumbang sebagian besar dari total biaya produksi, oleh karena itu besar biaya yang dikeluarkan untuk logistik menjadi faktor yang harus diperhatikan dalam meningkatkan daya saing perusahaan (mahendrawathi;2015).

Indeks Kinerja Logistik (LPI) adalah lembaga untuk menilai kinerja logistik di suatu negara (wbank;2017). Pada tahun 2018, Jerman telah menunjuk negara dengan kinerja terbaik (Arvis;2018). Sementara skor Indonesia pada 2018 naik 0,17 poin $(5,7 \%)$ menjadi 3,15 dari 2,98 (tahun 2016). Satu peningkatan dalam skor yang didukung oleh peningkatan dalam dimensi Pengiriman Internasional (meningkat sebesar 0,33 poin atau $11,4 \%)$, Infrastruktur $(0,25$ poin; $9,4 \%)$, dan Ketepatan Waktu (0,21 poin; 6,1\%). Selain itu, dimensi lain yang berkontribusi positif adalah
Pelacakan \& Penelusuran (0,11 poin; 3,4\%) dan Kompetensi Logistik (0,10 poin; 3,3\%). Sementara itu, dimensi Bea Cukai menurun 0,02 poin atau $0,7 \%$ (wbank;2018).

Pada perkembangan data di atas, Pelaku sektor logistik membutuhkan inovasi yang dapat meningkatkan daya saing dalam layanan (pane;2018). Warehouse Management Sytem (WMS) banyak digunakan dalam industri untuk meningkatkan efisiensi logistik (Adiono;2017). WMS juga merupakan bagian penting dari rantai pasok dan bertujuan untuk mengendalikan pergerakan dan penyimpanan material di dalam gudang. Sebuah gudang harus dilihat sebagai penyangga dalam rantai pasok dan sebagai tempat sementara untuk menyimpan persediaan (Richards;2017).

Masalah dalam logistik selalu dimulai dengan ketidakpastian dan risiko karena sifatnya yang tidak pasti (gooran;2018). Di Indonesia, pengembangan sistem berbasis logistik yang efisien merupakan tantangan bagi beberapa perusahaan (daryanto;2017).

Penelitian ini dilakukan untuk menganalisis data lokasi barang pada sistem WMS dan sistem LES menggunakan algoritma RANSAC untuk mengukur 
keakuratan data lokasi barang pada proses penempatan barang yang sesuai, Region Of Interest (ROI) untuk memperkecil ruang lingkup data lokasi barang. Di Indonesia, platform informasi logistik merupakan bagian yang sangat penting dalam manajemen dan kontrol operasi informasi logistik Platform dapat secara efektif meningkatkan fleksibilitas perusahaan yang baik (Yang;2017). Dalam penelitian ini menggunakan Random Sample Consensus Algorithm (RANSAC) yang merupakan bagian dari data dengan ukuran minimum yang dibutuhkan. Data diambil secara acak untuk pengambilan sampel (Tong;2015). Pengujian kelayakan metode ini dengan memproses 100 item lokasi data, untuk mengukur keakuratan data dari lokasi barang saat ini. Penelitian ini dimaksudkan untuk membantu proses penempatan barang dengan data lokasi yang tidak akurat di perusahaan logistik.

\section{KAJIAN PUSTAKA DAN PERUMUSAN HIPOTESIS}

Gudang digunakan sebagai tempat untuk fasilitas khusus dalam proses mendistribusikan barang dari pemasok (supplier) barang dan barang yang diproduksi kepada pengguna (end user) (Tong;2015). Pergudangan dirancang untuk mengontrol kegiatan pergudangan (pane;2019). Dalam beberapa tahun terakhir, pengecer online besar seperti Amon telah menggunakan batching dan zonasi dengan penyimpanan rak yang tinggi (Boysen;2018). Inventaris telah secara eksplisit memproses pengawasan pasokan, penyimpanan, dan aksesibilitas barang untuk memastikan investasi yang memadai. Menyediakan tanpa kelebihan pasokan berlebih (singh;2018). Dorongan pada sistem persediaan mensyaratkan prediksi sejumlah item yang dibutuhkan untuk memenuhi permintaan pengguna (end user) (nagle;2018). Warehouse Management System (WMS) merupakan elemen terpenting dari setiap rantai pasok. Proses pergudangan perlu untuk dikelola secara efisien untuk mencapai waktu throughput pesanan pendek, produk tinggi ketersediaan dan pengiriman cepat, yang merupakan dimensi penting dari layanan pelanggan (calzavara;2018). Warehouse Management System (WMS) adalah pendekatan yang diperlukan untuk setiap gudang. Sistem pergudangan secara otomatis memberikan hasil yang andal dibandingkan dengan sistem manual, WMS dirancang untuk membantu mengurangi biaya melalui proses gudang yang efektif (atieh;2016), dengan WMS aplikasi yang benar akan meningkatkan kondisi gudang (Fomina;2017). Operasi pergudangan umumnya dibantu oleh manajemen gudang sistem (WMS) (baruffaldi;2018). Dengan ini, semakin banyak penyedia 3PL berinvestasi dalam WMS (vouzas;2018) Penyedia Pihak Ketiga (3PL) adalah subjek penting lainnya, yang dapat meningkatkan kualitas produk secara langsung, dan yang dapat memiliki dampak nyata pada harga biaya produk (Govindan;2015), dan sebagai pusat logistik (Mindur;2018). Algoritma RANSAC digunakan untuk mengurangi noise dan mendapatkan estimasi data yang dapat diandalkan (olofsson;2018). Algoritma RANSAC dalam algoritma koreksi gambar adalah algoritma yang lebih klasik, yang ditandai dengan stabilitas tinggi, akurasi yang baik, dan kemampuan penyaringan yang baik untuk titik pencocokan kesalahan (cheng;2018). Algoritma RANSAC juga bekerja secara iteratif, yang mengarah ke masalah efisiensi rendah. Karena titik fitur awal dalam proses iteratif RANSAC dipilih secara acak, model transformasi yang dihasilkan mungkin tidak stabil (li;2017). Algoritma RANSAC adalah metode klasik untuk menghilangkan ketidakcocokan, yang memiliki keunggulan akurasi tinggi, keandalan tinggi, ketangguhan dan sebagainya. Sekarang banyak digunakan untuk memecahkan masalah visual seperti estimasi geometri epipolar, estimasi gerakan, dan struktur gerakan (alkowatly;2015) (wang;2016). Algoritma RANSAC juga dapat digunakan untuk memperkirakan suatu model dari suatu kumpulan data, di mana model yang diperkirakan dipenuhi oleh sebagian besar titik pencocokan (liu;2017). Namun, perhitungan seringkali tidak layak untuk dicoba (Yangpeng;2016).

Permasalahan yang diangkat dalam penelitian ini selalu dimulai dengan ketidakpastian lokasi barang dari 2 sistem, yaitu WMS dan LES. Untuk menjawab permasalahan ini memanfaatkan Region Of Interest (ROI) untuk memperkecil ruang lingkup data lokasi barang dan algoritma RANSAC untuk mengukur keakuratan data lokasi barang untuk proses penempatan barang yang sesuai dengan kebutuhan perusahaan. Penelitian ini dilakukan untuk menganalisis dan mengidentifikasi keakuratan lokasi barang dengan data lokasi barang pada WMS dan LES.

\section{METODE PENELITIAN}

Dalam penelitian ini menggunakan algoritma RANSAC dalam proses penghitungan akurasi data barang. Region of Interest (ROI) memperkecil ruang lingkup data lokasi barang di perusahaan logistik. Untuk menyelesaikan masalah tersebut perlu untuk menerapkan metodologi penelitian, yang ditunjukkan pada Gambar 1.

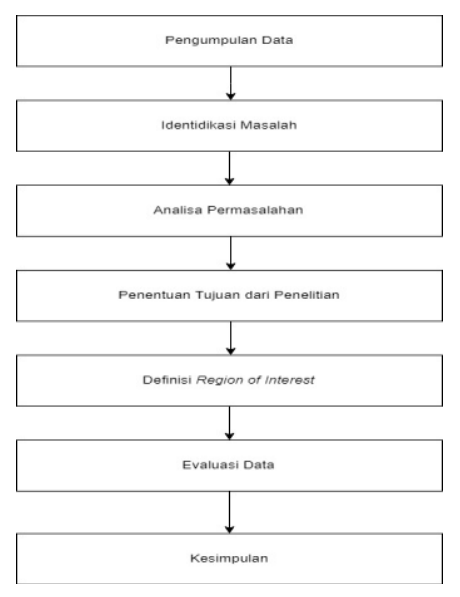

Gambar 1. Tahap - Tahap Yang Digunakan Pada Penelitian 


\section{Pengumpulan Data}

Pada tahap penelitian ini, mengumpulkan data dari data primer, data sekunder, wawancara, observasi dan studi pustaka sebagai data yang diperlukan untuk mendukung penelitian penulis.

\section{Identifikasi Masalah}

Pada tahap penelitian ini, akan mengidentifikasikan permasalahan yang terjadi di gudang, melihat masalah dalam penempatan barang, dan mereka yang membutuhkan data lokasi yang akurat.

\section{Analisa Masalah}

Pada tahap penelitian ini, akan menganalisis apa saja yang terjadi pada sistem manajemen pergudangan dan merumuskan langkah-langkah untuk masalah yang telah dilakukan dengan melakukan analisis seperti mengidentifikasi, memahami dan menganalisis.

\section{Penentuan Tujuan dan Penelitian}

Tujuan dan manfaat untuk memproses informasi menggunakan algoritma RANSAC, dengan itu dapat merampingkan tugas dari staff gudang dalam proses menempatkan barang dengan akurasi. Dengan adanya penelitian ini, diharapkan mampu mengatasi permasalahan pada gudang.

\section{Definisi Region Of Interest}

Pada tahap ini, Region of Interest (ROI) digunakan untuk memperkecil ruang lingkup data lokasi barang. Data tersebut digunakan untuk menghitung keakuratan akurasi data lokasi barang.

\section{Evaluasi Data}

Berdasarkan analisis hasil uji sistem maka dibuat nya kesimpulan dari hasil penelitian ini. Penyelesaian yang diperoleh dari studi validitas dan reliabilitas hasil tes diharapkan dapat memberikan jawaban dari tujuan penelitian ini. Kemudian penulis akan menawarkan saran yang dapat dipertimbangkan oleh perusahaan logistik jika analisis sistem ini akan dikembangkan lagi.

$$
k=\frac{\log (1-p)}{\log \left(1-w^{n}\right)}
$$

\section{Kesimpulan}

Hasil penelitian yang diperoleh dari analisis data menggunakan algoritma RANSAC, di mana hasil dari evaluasi data barang pada wms dengan les dengan dengan menunjukkan tingkat akurasi. Dengan hasil keakuratan data tersebut dapat membantu proses penempatan barang dengan data lokasi yang akurat. Maka hasil dari penelitian ini dapat digunakan oleh perusahaan logistik.

\section{ANALISIS DAN PERANCANGAN}

Dalam proses ini, meninjau data yang dihasilkan dari hasil data yang telah dilakukan untuk mendukung analisis. Penelitian ini menggunakan algoritma RANSAC, sehingga dapat memberikan manfaat untuk manajemen sistem operasi.

\section{Proses Bisnis Receiving Barang}

Proses bisnis receiving barang yang akan dianalisis berdasarkan proses bisnis yang berjalan saat ini, dengan tujuan menentukan proses baru dalam melakukan aktivitas penempatan barang, sehingga mempermudah peneliti dalam melakukan proses algoritma RANSAC untuk menentukan akurasi keakuratan data penempatan barang.

\section{Analisa Masalah}

Pada tahap ini akan menganalisa permasalahan dengan merumuskan langkah analisis masalah untuk memahami masalah yang telah ditentukan, adapun Teknik analisis yang digunakan sebagai berikut:

1. Identify: Permasalahan pada penelitian ini bagaimana mencocokkan data lokasi barang pada wms dan les dengan menggunakan algoritma RANSAC untuk melakukan perhitungan dan Region Of Interest (ROI) untuk memperkecil ruang lingkup data lokasi barang.

2. Understand: Data yang digunakan pada penelitian ini di dapatkan pada perusahaan logistik yang bergerak pada bidang manufaktur.

3. Analyze: Pada bagian operation system management masih kesulitan dalam proses penempatan barang, dikarenakan data lokasi barang yang tidak akurat. Penelitian ini menggunakan algoritma ransac untuk mengukur keakuratan data lokasi barang untuk proses penempatan barang

\section{Data Primer}

Data primer diperoleh dan dikumpulkan langsung dari sumbernya. Sumber data primer didapatkan dari hasil observasi lapangan. Data primer yang digunakan pada penelitian ini merupakan sebagian atribut dari keseluruhan data barang pada perusahaan logistik. Atribut yang digunakan adalah Part Used, Dloc, dan LES.

\section{Region Of Interest}

Pada tahap ini, ROI memproses 100 data lokasi barang dari data primer yang dimana pada data primer terdapat banyak kategori, dan peneliti membentuk data yang akan di proses berdasarkan data lokasi barang yang digunakan sebagai data sample, untuk menentukan akurasi keakuratan data pada wms dan les dengan menggunakan algoritma RANSAC. Hasil pencocokan data terdapat 87 data sesuai hasilnya adalah TRUE dan 13 data tidak sesuai hasilnya adalah FALSE.

\section{Evaluasi Data}

Pada tahap ini kelanjutan dari Region Of Interest, yang memanfaatkan data yang telah dibuat, untuk memproses perhitungan nilai akurasi data lokasi barang yang dalam perhitungan ini menggunakan rumus algoritma RANSAC. Flowchart algoritma Gambar 2, yang digunakan menggambarkan proses pengolahan data dari penelitian ini menjadi hasil yang sesuai dengan tujuan penelitian ini. 


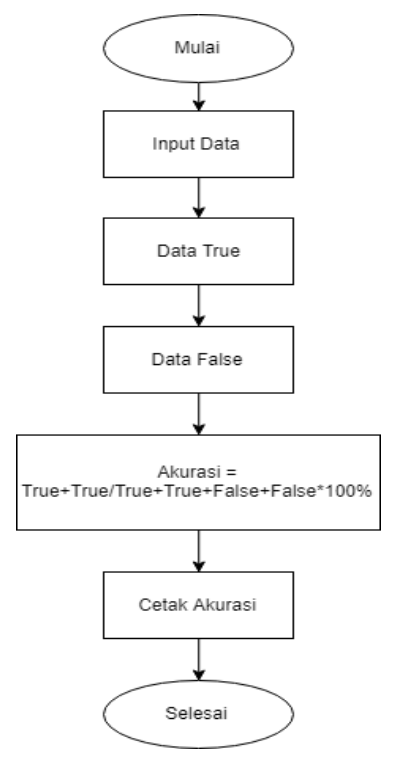

Gambar 2. Flowchart Algoritma

Perhitungan nilai untuk menentukan akurasi data dari rumus algoritma RANSAC adalah sebagai berikut Tabel 1.

\begin{tabular}{|c|c|c|}
\hline \multirow{2}{*}{ Aktual } & \multicolumn{2}{|c|}{ Akurasi Data } \\
\hline & DLOC & LES \\
\hline DLOC & TD (TRUE DLOC) & FD (FALSE DLOC) \\
\hline LES & FL (FALSE LES) & TL (TRUE LES) \\
\hline
\end{tabular}

Aktual adalah kepemilikan lokasi barang yang bersumber dari data primer. Jika hasil pencocokan lokasi dloc dan les sama maka hasilnya adalah true, jika hasil pencocokan terhadap dloc dan les tidak sama maka hasilnya false. Jumlah true dan false dapat dilihat pada Tabel 2. Berikut ini adalah hasil perhitungan keakuratan data penempatan barang:

Tabel 2. Hasil Perhitungan

\begin{tabular}{|c|c|c|}
\hline \multirow{2}{*}{ Aktual } & \multicolumn{2}{|c|}{ Akurasi Data } \\
\cline { 2 - 3 } & DLOC & LES \\
\hline DLOC & 87 & 13 \\
\hline LES & 13 & 87 \\
\hline
\end{tabular}

$$
\text { Akurasi }=\frac{87+87}{87+87+13+13}=\frac{174}{200}=0.87=87 \%
$$

Berdasarkan hasil dari perhitungan Tabel 2, maka didapatkan hasil akurasi data lokasi barang sebesar $87 \%$, dalam data lokasi penempatan barang yang berjalan saat ini. Yang dimana keakuratan lokasi barang pada wms dengan les dengan menggunakan algoritma RANSAC ini bisa digunakan untuk pencocokan data lokasi pada wms dan les yang dimana sering terjadi kesalahan dalam proses penempatan barang, dikarenakan data lokasi barang yang tidak akurat.

\section{Kesimpulan}

Setelah melakukan analisis dengan algoritma ransac untuk menentukan akurasi data lokasi barang, maka dapat disimpulkan sebagai berikut:

1. Terdapat banyak kekurangan terhadap kecocokan data lokasi DLOC WMS dengan LES (Logistics Execution System) yang dimana data lokasi yang cocok terdapat 87 data sedangkan data yang tidak cocok terdapat 13 data dari 100 data sample dengan memanfaatkan Region of Interest (ROI) untuk memperkecil jumlah data yang di proses, untuk melihat kecocokan data barang.

2. Hasil penelitian menggunakan Algoritma RANSAC untuk menentukan akurasi data lokasi barang dari 100 data sample, didapatkan hasil dari evaluasi data lokasi barang pada wms dan les, dengan tingkat akurasi keakuratan data lokasi barang sebesar $87 \%$.

\section{Saran}

Saran yang ingin disampaikan untuk pengembangan analisis pada penelitian ini sebagai berikut:

1. Penelitian dengan menggunakan algoritma RANSAC ini merupakan untuk menentukan akurasi lokasi data barang.

2. Penelitian ini dapat dikembangkan dengan menggunakan metode atau algoritma lainnya.

\section{DAFTAR PUSTAKA}

A. Daryanto et al. (2017). Logistics systems in the supply chain of agricultural products in indonesia. Agriculture and Development Notes, 8, 1-2.

A. Gooran, H. Racifi \& M. Rabani. (2018). Modeling risk and uncertainty in designing reverse logistics problem. Decision Science Letters, 7, no. 1, 13-2.

A. M. Atieh, H. Kaylani, Y. Al-abdallat, A. Qaderi, L. Ghoul, L. Jaradat, \& I. Hdairis. (2016). Performance improvement of inventory management system processes by an automated warehouse management system. Procedia CIRP, 41, 568 - 572.

A. Nagle, S. Fisher, S. Frazier, \& S. McComb. (2018). Streamlining a simulation center's inventory management. Clinical Simulation in Nursing, 18, 1-5.

C.Liu, Q. Shen, H. Pan, \& M. Li. (2017). Modelling and simulation: an improved ransac algorithm based on the relative angle information of samples. International Journal of Modelling, Identification and Control, 28, no. 2, 144-152.

D. Cheng \& Y. Pang. (2018). Research on sift image recognition algorithm combined with ransac. International Journal of Advanced Research in Computer Science, 9, no.1.

\section{KESIMPULAN DAN SARAN}


D. Singh \& A. Verma. (2018). Inventory management in supply chain. Materials Today: Proceedings, 5, no.2, 3867-3872.

E. Mahendrawath, T.Wasusri, H.M.Astuti \& A.Herdiyanti. (2015). The Service Quality of Indonesia's Logistics Service Provider in Preparation for ASEAN Economic Community. Industrial Engineering, Management Science and Applications, 647656.

F. Vouzas \& T. Katsogianni. (2018). Tqm implementation in $3 \mathrm{pl}$ organisations vs organisations with in-house logistics department: A literature review. The TQM Journal, 30, no. 6, 749-763.

G. Baruffaldi, R. Accorsi, \& R. Manzini. (2018). Warehouse management system customization and information availability in 3 pl companies: a decision-support tool. Industrial Management \& Data Systems.

G. Richards. (2017). Warehouse management: a complete guide to improving efficiency and minimizing costs in the modern warehouse. Kogan Page Publishers.

I. G. Fomina \& V. V. Samoylov. (2017). Applying of innovative methods in warehouse management. in 2017 IEEE Conference of Russian Young Researchers in Electrical and Electronic Engineering (EIConRus), Feb, 1337-1340.

J. -F. Arvis, L. Ojala, C. Wiederer, B. Shepherd, A. Raj, K. Dairabayeva \& T. Kiiski. (2018). Connecting to Compete 2018: Trade Logistics in the Global Economy. World Bank.

K. Govindan, H. Soleimani \& D. Kannan. (2015). Reverse logistics and closed-loop supply chain: A comprehensive review to explore the future. European Journal of Operational Research, 240, no.3, 603-626.

K. Olofson \& H. Olsson. (2018). Estimating tree stem density and diameter distribution in singlescan terrestrial laser measurements of field plots: a simulation study. Scandinavian Journal of Forest Research, 33, no.4, 365377.

L. Yangpeng, J. Ding, F. Wang, X. Long \& Z. Jiang. (2016). The fast recognition method for circle group based on regional data acquisition and sub-pixel technology. International Journal of Modelling, Identification and Control, 26, 152.

M. Calzavara, C. H. Glock, E. H. Grosse \& F. Sgarbossa. (2018). An integrated storage assignment method for manual order picking warehouses considering cost, workload and posture. International Journal of Production Research, 1-17.

M. Christopher. (2016). Logistics \& supply chain management. New Jersey : FT Press.
M. Mindur, K. Turon \& G. Sierpinski. (2018). The diversity of logistics centre concepts in europe. Logistics and Transport, 39, 53-58.

M. T. Alkowatly, V. Becerra \& W. Holderbaum. (2015). Body-centric modelling, identification, and acceleration tracking control of a quadrotor uav. International journal of modelling, identification and control, 24, no. 1, 29-41.

M. Yang, M. Mahmood, X. Zhou, S. Shafaq, \& L. Zahid. (2017). Design and implementation of cloud platform for intelligent logistics in the trend of intellectualization. China Communications, 14, no. 10, 180-191, Oct 2017.

N. Boysen, R. de Koster \& F. Weidinger. (2018). Warehousing in the e-commerce era: A survey. European Journal of Operational Research.

P. Liu, G. Yao, H. Cai \& Z. Yang. (2015). Design and implementation of warehouse management system based on b/s mode. in 2015 International Conference on Computer Science and Applications (CSA), Nov 2015, 146-150.

S. F. Pane, R. M. Awangga \& B. R. Azhari. (2018). Qualitative evaluation of rfid implementation on warehouse management system. Telkomnika, 16, no. 3 .

S. F. Pane, R. M. Awangga, B. R. Azhari \& G. R. Tartila. (2018). Rfid-based conveyor belt for improve warehouse operations. TELKOMNIKA (Telecommunication Computing Electronics and Control), 17, no. 2.

T. Adiono, H. Ega, H. Kasan \& C. S. Harimurti. (2017). Fast warehouse management system (wms) using rfid based goods locator system. in 2017 IEEE 6th Global Conference on Consumer Electronics (GCCE), Oct 2017, 12.

T. W. Bank. (2017). The logistics performance index. World Bank Group.

W. Bank. (2018). Global ranking the logistics performance index. World Bank Group.

X. Tong, Z. Ye, Y. Xu, S. Liu, L. Li, H. Xie \& T. Li. (2015). A novel subpixel phase correlation method using singular value decomposition and unified random sample consensus. IEEE Transactions on Geoscience and Remote Sensing, 53, no. 8, 4143-4156, Aug 2015.

X. Wang, S. Li, Y. Yu, L. Man \& J. Wang. (2016). Active contour-based colour image selective segmentation. International Journal of Modelling, Identification and Control, 25, no. $1,48-55$.

Y. Li, F. Li, K. Yang, C. Price \& Q. Shen. (2017). Remote sensing image registration based on gaussian-hermite moments and the pseudoransac algorithm. Remote Sensing Letters, 8, no. $12,1162-1171$. 